\title{
Effects of Smoking Intensity and Cessation on Inflammatory Markers in a Large Cohort of Active Smokers
}

\author{
Asha Asthana, Heather M. Johnson, MD, Megan E. Piper, PhD, Michael C. Fiore, MD, MPH, \\ Timothy B. Baker, PhD, and James H. Stein, MD \\ University of Wisconsin School of Medicine and Public Health; Madison, WI
}

\section{Abstract}

Background-Cigarette smoking has been associated with increases in C-reactive protein (CRP) and leukocyte counts (WBC); however, the effects of smoking intensity and smoking cessation on inflammatory markers have not been evaluated prospectively in a large, modern cohort of current smokers.

\begin{abstract}
Methods-WBC count and high-sensitivity CRP were measured in current smokers enrolled in a randomized, prospective clinical trial of five smoking cessation pharmacotherapies. Smoking intensity parameters included: cigarettes/day, pack-years, Fagerstrom Test of Nicotine Dependence (FTND) score, and carbon monoxide (CO) levels. CRP also was measured after 1 year with assessment of abstinence status.
\end{abstract}

Results-The 1,504 current smokers (58\% female) were mean (standard deviation): 44.7 (11.1) years old, smoked 21.4 (8.9) cigarettes/day and had a smoking burden of 29.4 (20.4) pack-years. Log (CRP) was not associated with any marker of smoking intensity, except for a weak correlation with pack-years $(\mathrm{r}=0.05, \mathrm{p}=0.047)$. In contrast, statistically significant correlations were observed between all 4 markers of smoking intensity and $\mathrm{WBC}$ count (all $\mathrm{p} \leq 0.011$ ). In multivariable models, waist circumference $(\mathrm{p}<0.001)$ and triglycerides $(\mathrm{p}<0.05)$, but no markers of smoking intensity, were associated with $\log (\mathrm{CRP})$. However, pack-years $(\mathrm{p}=0.002)$, cigarettes/day $(\mathrm{p}=0.013), \mathrm{CO}(\mathrm{p}<0.001)$, and FTND $(\mathrm{p}<0.001)$ were independently associated with WBC count. After 1 year, $\log (\mathrm{CRP})$ $(\mathrm{p}=0.296)$ and changes in $\log (\mathrm{CRP})(\mathrm{p}=0.455)$ did not differ between abstainers and continuing smokers.

Conclusions-Smoking intensity is associated with increased WBC count, but not CRP levels. Smoking cessation does not reduce CRP. The relationship between CRP and smoking intensity may be masked by CRP's stronger relationship with adiposity.

\section{Keywords \\ C-reactive protein; Inflammation; Leukocytes; Risk factors; Smoking}

\footnotetext{
Address for Correspondence: James H. Stein, MD, University of Wisconsin School of Medicine and Public Health, 600 Highland Avenue, G7/341 CSC (MC 3248), Madison, WI 53792, Phone: (608) 263-9648, Fax: (608) 263-0405, jhs@ medicine.wisc.edu.

Potential Conflicts of Interest

A Asthana, HM Johnson, ME Piper, and JH Stein have no conflicts to disclose.

MC Fiore - Over the last three years, Dr Fiore has served as an investigator in research studies at the University of Wisconsin that were funded by Pfizer, GlaxoSmithKline and Nabi Biopharmaceuticals. In 1998, the University of Wisconsin (UW) appointed Dr. Fiore to a named Chair funded by an unrestricted gift to UW from Glaxo Wellcome.

TB Baker - Research grants from Pfizer, GlaxoSmithKline, Nabi Biopharmaceuticals, and Sanofi

Publisher's Disclaimer: This is a PDF file of an unedited manuscript that has been accepted for publication. As a service to our customers we are providing this early version of the manuscript. The manuscript will undergo copyediting, typesetting, and review of the resulting proof before it is published in its final citable form. Please note that during the production process errors may be discovered which could affect the content, and all legal disclaimers that apply to the journal pertain.
} 


\section{Introduction}

Cigarette smoking is a powerful risk factor for atherosclerosis and cardiovascular disease (CVD). Approximately $36 \%$ of the population-attributable risk for myocardial infarction is directly attributable to smoking. ${ }^{1}$ Smoking cessation is associated with significant CVD risk reduction and mortality benefits. ${ }^{2-6}$ Atherogenesis and acute coronary syndromes are inflammatory processes; because cigarette smoking has been associated with systemic inflammation, it has been hypothesized that inflammation may be a mechanism by which cigarette smoking affects CVD. ${ }^{7,8} \mathrm{C}$-reactive protein (CRP) and white blood cell (WBC) count are circulating markers of systemic inflammation that have been associated with atherosclerosis and increased CVD risk. ${ }^{8,9}$ However, the extent to which the relationships between these markers and CVD risk are independent of traditional risk factors, such as smoking, obesity, and dyslipidemia is unclear. ${ }^{10,11}$

Previous investigations have demonstrated that increased CRP levels are a secondary effect of cigarette smoking and reflect tissue injury. ${ }^{10,12}$ CRP levels and WBC counts are higher among current smokers compared to never smokers. ${ }^{7,9,12-14}$ Positive, independent relationships between the number of cigarettes/day and elevated levels of CRP and WBC counts also have been described. ${ }^{8,9,13,15,16}$ However, previous studies of the effects of smoking on inflammatory markers tended to be small, frequently did not adjust for confounders that affect CRP levels (such as age, sex, adiposity, and physical activity) and may not be representative of contemporary smokers, who tend to be more overweight than historical cohorts. ${ }^{17}$ Several reports only evaluated cigarettes smoked per day, rather than other markers of smoking intensity including nicotine dependence and recent smoke exposure. Also, other studies did not follow changes in markers longitudinally and did not examine whether markers are affected by smoking cessation. This study examined the interrelationships between 4 markers of smoking intensity, CRP, and WBC counts in a large cohort of daily smokers and sought to determine if smoking cessation is associated with a reduction in CRP.

\section{Methods}

\section{Study Participants and Design}

Subjects were participants in a longitudinal, randomized, double-blind, placebo-controlled smoking cessation trial to evaluate the efficacy of five smoking cessation pharmacotherapies and to examine the natural history of continued smoking and smoking cessation (clinicaltrials.gov registration number NCT00332644). ${ }^{18}$ Participants were randomized to placebo or one of five smoking cessation interventions: nicotine lozenge, nicotine patch, sustained-release bupropion, nicotine patch plus nicotine lozenge, or bupropion plus nicotine lozenge. All participants received individual counseling sessions. ${ }^{18}$ Each subject's baseline and one year post-quit data were analyzed. Major inclusion criteria were: age $\geq 18$ years old, smoking at least 10 cigarettes/day for the previous 6 months, expired carbon monoxide (CO) level $>9 \mathrm{ppm}$, and stated motivation to try to quit smoking. Major exclusion criteria were: uncontrolled hypertension (blood pressure $>160 / 100 \mathrm{mmHg}$ ), myocardial infarction within the previous 4 weeks, drinking 6 or more alcoholic drinks on 6 or 7 days a week, history of seizure and/or serious head injury, use of contraindicated medications (monoamine oxidase inhibitors, bupropion, lithium, anticonvulsants, antipsychotics), and current pregnancy or breast-feeding. 18 This study was approved by the institutional review board at the University of Wisconsin School of Medicine and Public Health. All subjects provided written informed consent. 


\section{Study Procedures}

Subjects were recruited from communities in or around Madison and Milwaukee, Wisconsin, from January, 2005 to June, 2007. ${ }^{18}$ The baseline and one-year clinical trial visits included measurement of anthropometric data, fasting laboratory tests, and completion of validated questionnaires and interviews. The measurements performed are in the first column of Table 1. CRP was measured in all subjects at both visits. Evaluating the effects of smoking cessation on CRP levels was a pre-specified secondary analysis of this study. WBC count was measured at the baseline visit only and the analyses were performed in response to the CRP findings described below. Physical activity was measured using the long form of the International Physical Activity Questionnaire (IPAQ). ${ }^{19}$ Four parameters related to smoking intensity were evaluated: current cigarette smoking (cigarettes/day) and current pack-years (current cigarettes/day * number of years smoked) to describe current smoking burden, the Fagerstrom Test for Nicotine Dependence (FTND) ${ }^{20}$ to characterize nicotine dependence, and exhaled carbon monoxide (CO) levels to quantify smoking efficiency, recent smoking, and recent smoke exposure. Seven-day, CO-confirmed $(<10 \mathrm{ppm})$ point-prevalence abstinence was assessed one year after the target quit date. ${ }^{18,21,22}$

\section{Measurements of Inflammatory Markers}

Fasting blood samples were obtained by venipuncture and refrigerated. Plasma aliquots were isolated by centrifugation and frozen at -70 degrees. High-sensitivity CRP was measured by nephelometry on a Siemens Dimension Vista(r) 3000T Intelligent Lab System. Complete blood counts were performed on a Sysmex XE 2100 analyzer.

\section{Statistical Analysis}

Means, standard deviations, and ranges were used for descriptive statistics. Because of skew, CRP values were log-transformed. Pearson correlations were calculated to describe the unadjusted relationships between the smoking intensity parameters, inflammatory markers, and other relevant variables. For the cross-sectional analysis, multivariable linear regression models were created to identify independent predictors of $\log (\mathrm{CRP})$ and WBC count, using variables that had significant $(\mathrm{p}<0.10)$ correlations with these inflammatory markers. A basic model was created for each inflammatory marker that included age, sex, use of lipid-lowering medication, waist circumference, glucose, triglycerides, high-density lipoprotein cholesterol, and low-density lipoprotein cholesterol. Separate models were created by individually adding each of the four smoking intensity parameters to the basic model. Changes in $\log (\mathrm{CRP})$ after one year between treatment arms were evaluated using analysis of variance. A t-test was used to compare $\log (\mathrm{CRP})$ between those who successfully quit smoking ("abstainers") and those who relapsed. Differences in $\log (\mathrm{CRP})$ levels between continuing smokers and abstainers at one year also were analyzed by analysis of covariance, thereby controlling for potential baseline differences in $\log (\mathrm{CRP})$ between the two groups. Multivariable linear regression models were created for prediction of changes in log (CRP) after one year. Analyses were performed with SPSS software (Version 17.0, SPSS, Inc., Chicago, IL).

\section{Funding Sources}

This research was supported in part by grant P50 DA019706 from the National Institute on Drug Abuse to the University of Wisconsin-Center for Tobacco Research and Intervention, a Ruth L. Kirschstein National Research Service Award T32 HL07936 from the National Heart Lung and Blood Institute, and an Institutional Clinical and Translational Science Award KL2 RR025012. Medications for the study were provided by GlaxoSmithKline. The authors are solely responsible for the design and conduct of this study, all study analyses, the drafting and editing of the paper and its final contents." 


\section{Results}

\section{Subject Characteristics}

Baseline subject characteristics are in Table I. The 1,504 participants (58\% female, $84 \%$ white) were mean (standard deviation): 44.7 (11.1) years old, smoked 21.4 (8.9) cigarettes/day and had a smoking burden of 29.4 (20.4) pack-years. The highest level of education attained was college-level training or graduation in $70.8 \% ; 23.6 \%$ graduated from high school. FTND scores were 5.4 (2.1) and CO levels 26 (12.5) ppm. Mean CRP was 2.1 (11.0) $\mathrm{mg} / \mathrm{L}$ (median 0.5, inter-quartile range $0.2-1.9 \mathrm{mg} / \mathrm{L})$, mean $\log (\mathrm{CRP})$ was $0.18(0.64) \mathrm{mg} / \mathrm{L}$, and mean WBC 7.6 (2.2) $\mathrm{k} / \mu \mathrm{l}$. The mean body-mass index was $29.0(6.5) \mathrm{kg} / \mathrm{m}^{2}$ and waist circumference $96(16.2)$ $\mathrm{cm}$. On average, subjects consumed $16.0(23.9)$ alcohol-containing beverages a month. Total cholesterol and LDL-C levels were normal; however, high-density lipoprotein cholesterol levels were low and triglycerides were high-normal. ${ }^{17} \mathrm{Men}$ had lower high-density lipoprotein cholesterol (36 [11.6] mg/dL) than women $(46$ [13.4] mg/dL) ( $<<0.001)$; however, $\log (\mathrm{CRP})$ and WBC counts did not differ between the sexes $(\mathrm{p}=0.102)$. Only $11 \%$ of the participants reported taking lipid-lowering medications. ${ }^{17}$

\section{Correlations with Inflammatory Markers at Baseline}

Correlations among CRP, WBC, smoking intensity parameters, and other variables are in Table II. $\log (\mathrm{CRP})$ and WBC count were correlated modestly $(r=0.17, \mathrm{p}<0.001) . \log (\mathrm{CRP})$ was not associated with any marker of smoking intensity, except for a weak correlation with pack-years $(\mathrm{r}=0.05, \mathrm{p}=0.047)$. The strongest correlates of $\log (\mathrm{CRP})$ were waist circumference $(\mathrm{r}=0.30$, $\mathrm{p}<0.001)$ and body-mass index $(\mathrm{r}=0.30, \mathrm{p}<0.001) . \log (\mathrm{CRP})$ also was modestly but significantly correlated with education level, systolic and diastolic blood pressure, glucose, hemoglobin $\mathrm{A}_{1} \mathrm{C}$, low-density lipoprotein cholesterol, and high-density lipoprotein cholesterol.

In contrast to CRP, statistically significant, modest correlations were observed between all 4 markers of smoking intensity and WBC count (all $\mathrm{p} \leq 0.007)$. In addition to the smoking intensity parameters, WBC count was significantly correlated with body-mass index, waist circumference, diastolic blood pressure, hemoglobin $\mathrm{A}_{1} \mathrm{C}$, hemoglobin, and all lipid fractions.

\section{Multivariable Predictors of Inflammatory Markers at Baseline}

The best multivariable model for $\log (\mathrm{CRP})$ among current smokers included waist circumference $(\mathrm{p}<0.001)$ and triglycerides $(\mathrm{p}=0.051)$, but no markers of smoking intensity. In contrast, the multivariable models predicting WBC count all included waist circumference, sex, triglycerides, hemoglobin, and hemoglobin $\mathrm{A}_{1} \mathrm{C}$ and then one of the smoking intensity variables: pack-years ( $\mathrm{p}=0.009)$, cigarettes/day ( $\mathrm{p}=0.037), \mathrm{CO}(\mathrm{p}<0.001)$, or FTND $(\mathrm{p}<0.001)$. The best multivariable model for WBC count among current smokers included $\mathrm{CO}(\mathrm{p}<0.001)$ as the smoking measure (see Table III). Models for the other markers of smoking intensity had similar adjusted $\mathrm{R}^{2}$ values and independent contributions similar to CO.

\section{Changes in CRP after Smoking Cessation}

CRP levels from the baseline and 1-year post-quit visits were available for $95 \%$ of the 973 subjects that returned for a year 1 visit. After 1 year, $36.2 \%$ of returning subjects had successfully abstained from smoking. $\log (\mathrm{CRP})$ was similar among abstainers $(0.36$ [0.46] $\mathrm{mg} / \mathrm{L})$ and continuing smokers $(0.32[0.50] \mathrm{mg} / \mathrm{L}),(\mathrm{p}=0.296)$. Change in $\log (\mathrm{CRP})$ also was similar among continuing smokers and abstainers $(\mathrm{p}=0.455)$ and did not differ between treatment arms $(\mathrm{p}=0.820)$. Smoking status after one year also did not predict $\log (\mathrm{CRP})$ values at the 1 -year post quit visit (effect size $=0.003, \mathrm{p}_{\mathrm{ANCOVA}}=0.125$ ). Changes in levels of CVD risk factors in this study (such as lipids, blood pressures, glucose, etc.) have been reported 
previously. ${ }^{6}$ In univariate analysis, change in $\log (\mathrm{CRP})$ was weakly correlated with change in high-density lipoprotein cholesterol $(r=-0.10, p=0.004)$, but no other variables. Abstainers had greater increases in waist circumference $(3.0 \mathrm{vs} .1 .0 \mathrm{~cm}, \mathrm{p}<0.001)$, body-mass index (1.6 vs. $\left.0.2 \mathrm{~kg} / \mathrm{m}^{2}, \mathrm{p}<0.001\right)$, and high-density lipoprotein cholesterol ( 2.8 vs. $\left.0.4 \mathrm{mg} / \mathrm{dL}, \mathrm{p}<0.001\right)$ compared to continuing smokers. In multivariable analysis, changes in $\log (\mathrm{CRP})$ after 1 year were independently associated with baseline educational status $(\beta=0.09, p=0.007)$, baseline waist circumference $(\beta=-0.09, \mathrm{p}=0.013)$, and change in high-density lipoprotein cholesterol ( $\beta=-0.09, p=0.008$ ), but not smoking status or any baseline marker of smoking intensity. Similarly, age, sex, race, and changes in body-mass index, waist circumference, blood pressure, low-density lipoprotein cholesterol, and glucose were not independently associated with changes in $\log (\mathrm{CRP})$.

\section{Discussion}

In this large cohort of current smokers enrolled in a smoking cessation clinical trial, we observed divergent associations between two inflammatory markers and several measures of smoking intensity. CRP levels were not associated strongly with any markers of smoking intensity; however, we observed modest associations between WBC count and all four markers of smoking intensity that we examined. The associations between WBC count and the markers of smoking intensity remained statistically significant even after controlling for waist circumference, sex, triglycerides, hemoglobin, and hemoglobin $\mathrm{A}_{1} \mathrm{C}$. Longitudinal follow-up surprisingly showed no differences in CRP levels between abstainers or continued smokers.

Exposure to cigarette smoke increases oxidative stress which may lead to vascular inflammation. Previous studies have shown that CRP levels are elevated in current smokers compared to nonsmokers; however, CRP values in our subjects were normal, despite being, on average, overweight. ${ }^{23}$ Associations between cigarettes smoked per day, CRP levels, and WBC counts have been described previously in observational cohorts. $8,9,13,15,16 \mathrm{We}$ confirmed independent associations between WBC count and cigarettes smoked per day, packyears, and $\mathrm{CO}$ levels and described, for the first time, an association between a measure of nicotine addiction (the FTND score) and the WBC count. However, we were not able to replicate previously reported associations between these markers of smoking intensity and CRP in our study. We also did not observe a long-term improvement in CRP with smoking cessation.

Because of the design of our study, we can only speculate on the reasons for the apparently divergent relationships between these two inflammatory markers and markers of smoking intensity. Because our subjects were participants in a clinical trial of smoking cessation interventions, all of our subjects smoked at least 10 cigarettes per day, and we did not have a non-smoking control group. It is possible that any cigarette smoking at all increases CRP, a highly sensitive marker of subclinical inflammation, so a dose-response relationship with markers of smoking intensity was not seen. This hypothesis is unlikely, however, because smoking cessation also was not associated with reductions in CRP. A more likely explanation is that CRP, in comparison to WBC count, is more affected by parameters such as central adiposity than smoking intensity. Indeed, the strongest correlates of CRP at baseline were waist circumference, body-mass index, and other markers associated with central adiposity and the Metabolic Syndrome, including glucose, hemoglobin $\mathrm{A}_{1} \mathrm{C}$, blood pressure, and low highdensity lipoprotein cholesterol. In multivariable models, waist circumference and triglycerides, but no markers of smoking intensity were independently associated with CRP, suggesting that visceral adiposity and its metabolic effects are more powerful determinants of CRP levels than are smoking intensity and its consequences. After one year, changes in high-density cholesterol independently influenced CRP levels, but markers of smoking intensity did not. Since abstainers gained more weight than continuing smokers, it appears that the effects of adiposity outweighed and perhaps masked the effects of smoking intensity on CRP. 
WBC count, however, is less strongly associated with adiposity, so its relationship with each of the markers of smoking intensity we evaluated was statistically significant and independent. It also is possible that smoking disproportionately causes inflammation in tissues that more directly affect the WBC count (such as the lungs) than the arteries. Given the heightened interest in using CRP as a marker of CVD risk, these findings are important. ${ }^{8}$ Although smoking cessation reduces CVD risk, ${ }^{2-6}$ patients and physicians should expect CRP levels to improve after smoking cessation. For current smokers, changes in CRP with abstinence appear to be disassociated from the observed improvements in CVD risk observed after smoking cessation. $4-6$

\section{Limitations}

Because this was a randomized clinical trial of smoking cessation interventions, there were no non-smoking controls, so we could not determine the extent to which WBC and CRP levels among current smokers differed from non-smokers, or the extent to which changes in CRP among abstainers approached levels seen in non-smokers or former smokers. In our study, approximately $35 \%$ of subjects did not return for their one-year follow-up visit, which is consistent with the 30-43\% one year drop-out rates reported in other recent clinical trials of smoking cessation pharmacotherapy. ${ }^{24,25}$ Compared to those who did not return for their one year visit, those with one year data were approximately one year older $(\mathrm{p}=0.032)$ and were more likely to be male $(\mathrm{p}=0.032)$, but had similar race distributions $(\mathrm{p}=0.365)$ and baseline cigarettes smoked per day $(\mathrm{p}=0.357)$ than those who did not return. Also, WBC counts were not available for all subjects' samples and were not collected until after the study was started. Because WBC values were not obtained at the 1-year follow-up visit, we could not evaluate the effects of smoking cessation on WBC count. The significant relationship between educational status and CRP may be due to associations between educational status and a variety of factors known to affect health and health-relevant behaviors including health knowledge, health care quality, medication adherence, diet, and drug and alcohol use, among others. ${ }^{26-}$ 28 Thus, educational status may serve as a proxy for other unmeasured factors that play a more direct causal role in influencing CRP levels.

\section{Conclusions}

In this large cohort of active smokers, smoking intensity was independently associated with the WBC count but not CRP levels, and smoking cessation did not reduce CRP levels. The relationship between CRP and smoking intensity may be masked by CRP's stronger relationship with adiposity.

\section{Acknowledgments}

Financial Support

This research was supported in part by grant P50 DA019706 from the National Institute on Drug Abuse to the University of Wisconsin-Center for Tobacco Research and Intervention. Heather M. Johnson was supported by the Ruth L. Kirschstein National Research Service Award T32 HL07936 from the National Heart Lung and Blood Institute. Megan E. Piper was supported by an Institutional Clinical and Translational Science Award KL2 RR025012. Dr. Baker was supported by grant K05 CA139871 from the National Cancer Institute. Medications for the study were provided by GlaxoSmithKline.

\section{Reference List}

1. Yusuf S, Hawken S, Ounpuu S, et al. Effect of potentially modifiable risk factors associated with myocardial infarction in 52 countries (the INTERHEART study): case-control study. Lancet 2004;364:937-52. [PubMed: 15364185] 
2. Doll R, Peto R, Boreham J, et al. Mortality in relation to smoking: 50 years' observations on male British doctors. BMJ 2004;328:1519. [PubMed: 15213107]

3. Freund KM, Belanger AJ, D'Agostino RB, et al. The health risks of smoking. The Framingham Study: 34 years of follow-up. Ann Epidemiol 1993;3:417-24. [PubMed: 8275219]

4. Rosenberg L, Kaufman DW, Helmrich SP, et al. The risk of myocardial infarction after quitting smoking in men under 55 years of age. N Engl J Med 1985;313:1511-14. [PubMed: 4069159]

5. Rosenberg L, Palmer JR, Shapiro S. Decline in the risk of myocardial infarction among women who stop smoking. N Engl J Med 1990;322:213-17. [PubMed: 2294448]

6. Johnson JM, Gossett L, Piper ME, et al. Effects of smoking and smoking cessation on endothelial function: One-year outcomes from a randomized clinical trial. Journal of the American College of Cardiology 2010:55. (in press).

7. Yasue H, Hirai N, Mizuno Y, et al. Low-grade inflammation, thrombogenicity, and atherogenic lipid profile in cigarette smokers. Circ J 2006;70:8-13. [PubMed: 16377917]

8. Pearson TA, Mensah GA, Alexander RW, et al. Markers of inflammation and cardiovascular disease: application to clinical and public health practice: A statement for healthcare professionals from the Centers for Disease Control and Prevention and the American Heart Association. Circulation 2003;107:499-511. [PubMed: 12551878]

9. Hansen LK, Grimm RH Jr, Neaton JD. The relationship of white blood cell count to other cardiovascular risk factors. Int J Epidemiol 1990;19:881-88. [PubMed: 2084016]

10. Danesh J, Collins R, Appleby P, et al. Association of fibrinogen, C-reactive protein, albumin, or leukocyte count with coronary heart disease: meta-analyses of prospective studies. JAMA 1998;279:1477-82. [PubMed: 9600484]

11. Miller M, Zhan M, Havas S. High attributable risk of elevated C-reactive protein level to conventional coronary heart disease risk factors: the Third National Health and Nutrition Examination Survey. Arch Intern Med 2005;165:2063-68. [PubMed: 16216995]

12. Hastie CE, Haw S, Pell JP. Impact of smoking cessation and lifetime exposure on C-reactive protein. Nicotine Tob Res 2008;10:637-42. [PubMed: 18418786]

13. Bazzano LA, He J, Muntner P, et al. Relationship between cigarette smoking and novel risk factors for cardiovascular disease in the United States. Ann Intern Med 2003;138:891-97. [PubMed: 12779299]

14. Ohsawa M, Okayama A, Nakamura M, et al. CRP levels are elevated in smokers but unrelated to the number of cigarettes and are decreased by long-term smoking cessation in male smokers. Prev Med 2005;41:651-56. [PubMed: 15917065]

15. Wannamethee SG, Lowe GD, Shaper AG, et al. Associations between cigarette smoking, pipe/cigar smoking, and smoking cessation, and haemostatic and inflammatory markers for cardiovascular disease. Eur Heart J 2005;26:1765-73. [PubMed: 15817606]

16. Rohde LE, Hennekens CH, Ridker PM. Survey of C-reactive protein and cardiovascular risk factors in apparently healthy men. Am J Cardiol 1999;84:1018-22. [PubMed: 10569656]

17. Gossett LK, Johnson HM, Piper ME, et al. Smoking Intensity and Lipoprotein Abnormalities in Active Smokers. J Clin Lipidol 2009;3:372-78. [PubMed: 20161531]

18. Piper ME, Smith SS, Schlam TR, et al. A randomized placebo-controlled clinical trial of 5 smoking cessation pharmacotherapies. Arch Gen Psychiatry 2009;66:1253-62. [PubMed: 19884613]

19. Craig CL, Marshall AL, Sjostrom M, et al. International physical activity questionnaire: 12-country reliability and validity. Med Sci Sports Exerc 2003;35:1381-95. [PubMed: 12900694]

20. Heatherton TF, Kozlowski LT, Frecker RC, et al. The Fagerstrom Test for Nicotine Dependence: a revision of the Fagerstrom Tolerance Questionnaire. Br J Addict 1991;86:1119-27. [PubMed: 1932883]

21. Murray RP, Connett JE, Istvan JA, et al. Relations of cotinine and carbon monoxide to self-reported smoking in a cohort of smokers and ex-smokers followed over 5 years. Nicotine Tob Res 2002;4:28794. [PubMed: 12215237]

22. Velicer WF, Prochaska JO, Rossi JS, et al. Assessing outcome in smoking cessation studies. Psychol Bull 1992;111:23-41. [PubMed: 1539088]

23. Bermudez EA, Rifai N, Buring JE, et al. Relation between markers of systemic vascular inflammation and smoking in women. Am J Cardiol 2002;89:1117-19. [PubMed: 11988205] 
24. Gonzales D, Rennard SI, Nides M, et al. Varenicline, an alpha4beta2 nicotinic acetylcholine receptor partial agonist, vs sustained-release bupropion and placebo for smoking cessation: a randomized controlled trial. JAMA 2006;296:47-55. [PubMed: 16820546]

25. Jorenby DE, Hays JT, Rigotti NA, et al. Efficacy of varenicline, an alpha4beta2 nicotinic acetylcholine receptor partial agonist, vs placebo or sustained-release bupropion for smoking cessation: a randomized controlled trial. JAMA 2006;296:56-63. [PubMed: 16820547]

26. Cohen BE, Panguluri P, Na B, et al. Psychological risk factors and the metabolic syndrome in patients with coronary heart disease: findings from the Heart and Soul Study. Psychiatry Res 2010;175:13337. [PubMed: 19969373]

27. Govil SR, Weidner G, Merritt-Worden T, et al. Socioeconomic status and improvements in lifestyle, coronary risk factors, and quality of life: the Multisite Cardiac Lifestyle Intervention Program. Am J Public Health 2009;99:1263-70. [PubMed: 18923113]

28. Yarnell J, Yu S, McCrum E, et al. Education, socioeconomic and lifestyle factors, and risk of coronary heart disease: the PRIME Study. Int J Epidemiol 2005;34:268-75. [PubMed: 15319403] 
Table I

Subject Characteristics at baseline $(\mathrm{N}=1504)$

\begin{tabular}{|c|c|c|}
\hline & Mean (standard deviation) & Range \\
\hline Age (years) & $44.7(11.1)$ & $18-79$ \\
\hline Sex (\% male) & 42 & - \\
\hline Race (\% white) & 84 & - \\
\hline Body-mass index $\left(\mathrm{kg} / \mathrm{m}^{2}\right)$ & $29.0(6.5)$ & $15.5-69.2$ \\
\hline Waist circumference $(\mathrm{cm})$ & $95.9(16.2)$ & $34-197$ \\
\hline Alcohol consumption (drinks/month) & $16.0(23.9)$ & $0-168$ \\
\hline \multicolumn{3}{|l|}{ Markers of smoking intensity* } \\
\hline Current smoking (cigs/day) & $21.4(8.9)$ & $1-80$ \\
\hline Smoking burden (current pack-yrs) & $29.4(20.4)$ & $0-156$ \\
\hline Fagerström Test of Nicotine Dependence Score & $5.4(2.1)$ & $0-10$ \\
\hline Carbon monoxide (ppm) & $25.7(12.5)$ & $1-110$ \\
\hline $\log (\mathrm{CRP})(\mathrm{mg} / \mathrm{L})$ & $0.32(1.04)$ & $0-2.60$ \\
\hline White blood cell count (K/ul) & $7.6(2.2)$ & $3-17$ \\
\hline Systolic blood pressure $(\mathrm{mmHg})$ & $119.4(14.4)$ & $80-178$ \\
\hline Diastolic blood pressure $(\mathrm{mmHg})$ & $74.3(10.1)$ & $42-110$ \\
\hline Glucose (mg/dL) & $94.9(17.7)$ & $1-258$ \\
\hline Hemoglobin $\mathrm{A}_{1} \mathrm{C}(\%)$ & $5.6(.641)$ & $1-11$ \\
\hline Hemoglobin $(\mathrm{g} / \mathrm{dL})$ & $15.0(1.7)$ & $10-48$ \\
\hline \multicolumn{3}{|l|}{ Lipids } \\
\hline Total cholesterol (mg/dL) & $183.9(35.4)$ & $76-341$ \\
\hline Low-density lipoprotein cholesterol (mg/dL) & $118.9(30.6)$ & $26-250$ \\
\hline High-density lipoprotein cholesterol (mg/dL) & $41.9(13.5)$ & $14-103$ \\
\hline Triglycerides (mg/dL) & $143.3(101.7)$ & $27-1460$ \\
\hline Use of lipid-lowering medications (\%) & $11 \%$ & - \\
\hline
\end{tabular}

$\mathrm{CRP}=\mathrm{C}$-reactive protein 
Table II

Correlations with Inflammatory Markers at Baseline

\begin{tabular}{|l|c|c|c|c|}
\hline & \multicolumn{2}{|c|}{$\log (\mathbf{C R P})$} & \multicolumn{2}{c|}{ WBC Count } \\
\hline & $\mathbf{r}$ & $\mathbf{p}$ & $\mathbf{r}$ & $\mathbf{p}$ \\
\hline Education level & -0.09 & $<\mathbf{0 . 0 0 1}$ & -0.00 & 0.910 \\
\hline Body-mass index & 0.30 & $<\mathbf{0 . 0 0 1}$ & 0.12 & $\mathbf{0 . 0 0 1}$ \\
\hline Waist circumference & 0.30 & $<\mathbf{0 . 0 0 1}$ & 0.12 & $\mathbf{0 . 0 0 1}$ \\
\hline Cigarettes/day & 0.05 & 0.055 & 0.11 & $\mathbf{0 . 0 0 1}$ \\
\hline Current pack-years & 0.05 & $\mathbf{0 . 0 4 7}$ & 0.01 & $\mathbf{0 . 0 0 7}$ \\
\hline Fagerstrom test of Nicotine Dependence score & 0.03 & 0.258 & 0.14 & $<\mathbf{0 . 0 0 1}$ \\
\hline Carbon Monoxide & -0.05 & 0.071 & 0.12 & $<\mathbf{0 . 0 0 1}$ \\
\hline Systolic blood pressure & 0.15 & $<\mathbf{0 . 0 0 1}$ & -0.04 & 0.295 \\
\hline Diastolic blood pressure & 0.14 & $<\mathbf{0 . 0 0 1}$ & 0.12 & $\mathbf{0 . 0 0 1}$ \\
\hline Glucose & 0.12 & $<\mathbf{0 . 0 0 1}$ & 0.02 & 0.595 \\
\hline Hemoglobin A $\mathrm{C}$ & 0.14 & $<\mathbf{0 . 0 0 1}$ & 0.07 & $\mathbf{0 . 0 0 6}$ \\
\hline Total cholesterol & 0.02 & 0.475 & 0.08 & $\mathbf{0 . 0 3 1}$ \\
\hline Low-density lipoprotein cholesterol & 0.06 & $\mathbf{0 . 0 2 5}$ & 0.09 & $\mathbf{0 . 0 1 7}$ \\
\hline High-density lipoprotein cholesterol & -0.13 & $<\mathbf{0 . 0 0 1}$ & -0.12 & $\mathbf{0 . 0 0 1}$ \\
\hline Triglycerides & 0.03 & 0.221 & 0.13 & $<\mathbf{0 . 0 0 1}$ \\
\hline Hemoglobin & 0.00 & 0.963 & 0.08 & $\mathbf{0 . 0 3 9}$ \\
\hline Log(CRP) & - & - & 0.17 & $<\mathbf{0 . 0 0 1}$ \\
\hline White blood cell count & 0.17 & $<\mathbf{0 . 0 0 1}$ & - & - \\
\hline
\end{tabular}

$\mathrm{CRP}=\mathrm{C}$-reactive protein 
Table III

Multivariable Model for Prediction of Baseline White Blood Cell Count

\begin{tabular}{|l|c|c|c|c|}
\hline & Beta & Standardized Beta & Standard Error & p-value \\
\hline Constant & 2.91 & - & 1.39 & 0.036 \\
\hline Age & -0.02 & -0.08 & 0.01 & 0.039 \\
\hline Sex & 0.76 & 0.18 & 0.19 & $<0.001$ \\
\hline Race & -0.93 & -0.15 & 0.23 & $<0.001$ \\
\hline Waist Circumference $(\mathrm{cm})$ & 0.01 & 0.11 & 0.01 & 0.008 \\
\hline Hemoglobin $(\mathrm{g} / \mathrm{dL})$ & 0.12 & 0.10 & 0.05 & 0.019 \\
\hline Hemoglobin $\mathrm{A}_{1} \mathrm{C}(\%)$ & 0.36 & 0.10 & 0.16 & 0.021 \\
\hline Triglycerides $(\mathrm{mg} / \mathrm{dL})$ & 0.00 & 0.10 & 0.00 & 0.024 \\
\hline High-density lipoprotein cholesterol $(\mathrm{mg} / \mathrm{dL})$ & -0.01 & -0.06 & 0.01 & 0.148 \\
\hline Low-density lipoprotein cholesterol $(\mathrm{mg} / \mathrm{dL})$ & 0.00 & 0.02 & 0.00 & 0.521 \\
\hline Carbon monoxide $(\mathrm{ppm})$ & 0.25 & 0.16 & 0.06 & $<0.001$ \\
\hline
\end{tabular}

